\title{
Barotrauma Induced Incus Dislocation
}

\author{
Yasemin Küçükç̣iloğlv (1), Süha Halil Akpınar (1), Sertan Gezgin (1), Khadija Ahmadova (1) \\ Department of Radiology, Near East University School of Medicine, Nicosia, Cyprus
}

ORCID IDs of the authors: Y.K. 0000-0002-I572-1375; S.H.A. 0000-000I-9248-6658; S.G. 0000-0002-5936-5392; K.A. 0000-0002-6450457X.

Cite this article as: Küçükçiloğlu Y, Akpınar SH, Gezgin S, Ahmadova K. Barotrauma Induced Incus Dislocation. Cyprus J Med Sci 2018; 3(3): 200-I.

Ossicular chain injuries are infrequent complications mostly caused by skull trauma and penetrating injury through the external auditory meatus. Blast, barotrauma and lightning are the other occasional causes.

Keywords: Ossicular chain, incus dislocation, barotrauma

\section{INTRODUCTION}

Ossicular chain injuries are rare complications of skull trauma through the temporal bone. Penetrating injury through the external auditory meatus and barotrauma are other frequent causes. Ossicular injury should be considered in patients with persistant hearing loss following trauma.

High-resolution CT is the method of choice for the evaluation of ossicular chain.

In the present report, we present high-resolution CT findings of incus dislocation in a scuba diver.

\section{CASE PRESENTATION}

A 20-year-old male scuba diver with hearing loss in his right ear was refered to our department. The patient denied any history of trauma. Otoscopic examination revealed a bony protrusion abutting the tympanic membrane in the right ear. High-resolution computerized tomography (256-detector multislice CT scanner, Somatom Definition Flash, Siemens Healthcare, Erlangen, Germany) demonstrated the dislocated incus protruding from the external auditory canal (Figures I and 2).

Written consent was obtained from the patient.

\section{DISCUSSION}

Ossicular chain injuries have various etiologies. The main cause is skull trauma (I, 2). Penetrating injury through the external auditory meatus (cotton-tipped applicators, stone, etc.); surgical trauma; blast; barotrauma through the external auditory canal or through the Eustachian tube; and lightning are the other causes (2).

Traumatic ossicular injuries are usually associated with longitudinal temporal bone fractures $(\mathrm{I}, 3)$. Temporary hearing loss following trauma is frequent due to tympanic membrane perforation or hemotympanium (4). Ossicular injury should be considered when conductive hearing loss lasts for two months following trauma $(3,5)$.

Types of the ossicular injuries include incudostapedial joint separation; incudomalleolar joint separation; incus dislocation; malleoincudal complex dislocation; stapediovestibular dislocation; and fractures of malleus, incus, and stapes (I). Incudostapedial joint separation is the most frequently occurring type of the ossicular injuries and dislocations are more common than fractures $(5,6)$. 

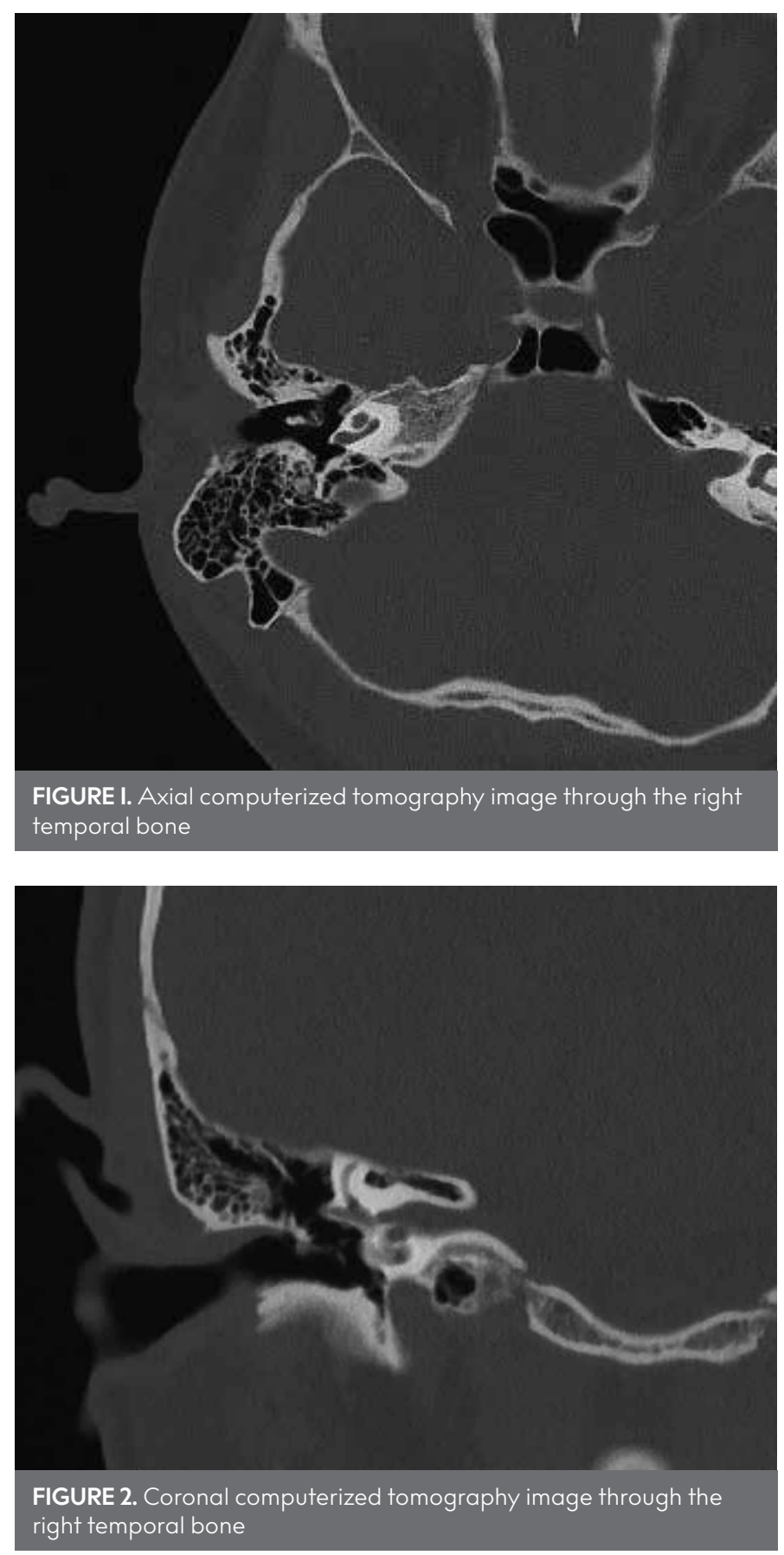

Incus is more vulnerable to traumatic injury, being the heaviest and weakly anchored ossicule, while malleus is stabilised by the tensor tympani tendon and stapes by the stapedial tendon (2, $6,7)$. Dislocated incus may remain in the epitympanic recess or prolapse into the hypotympanium or external auditory canal (2).

High-resolution CT is the method of choice for evaluation of the ossicular chain patologies (l,3). Axial and coronal planes are necessary for identifying the position of the incus and its relationship with the malleus and stapes.

Informed Consent: Written informed consent was obtained from the patient who participated in this study.

Peer-review: Externally peer-reviewed.

Author Contributions: Concept - Y.K., K.A.; Design - S.G.; Supervision S.H.A.; Resource - Y.K.; Materials - Y.K., K.A.; Data Collection and/or Processing - Y.K.; Analysis and/or Interpretation - Y.K.; Literature Search Y.K.; Writing - Y.K.; Critical Reviews - Y.K., S.H.A.

Conflict of Interest: The authors have no conflicts of interest to declare.

Financial Disclosure: The authors declared that this study has received no financial support.

\section{REFERENCES}

I. Stephan AL, Isaacson JE. Incudomalleolar Joint Separation. Am J Otol 2000; 21: 284-5. [CrossRef]

2. Meriot P, Veillon F, Garcia JF, Nonent M, Jezequel J, Bourjat P, et al CT Appearances Of Ossicular Injuries. Radiographics 1997; 17: 144554. [CrossRef]

3. Sasindran V, Joseph A, Babu B, George P. A Case Of Posttraumatic Incudomalleolar Disruption. Indian J Otol 2014; 20: 89-91. [CrossRef]

4. Coulier B, Lamarque C, Dejardin S. 2D and 3D CT Diagnosis Of Traumatic Incudostapedial Joint Separation. J Belg Soc Radiol 2015; 99: II6-7. [CrossRef]

5. Yetiser S, Hidir Y, Birkent H, Satar B, Durmaz A. Traumatic Ossicular Dislocations: Etiology And Management. Am J Otolaryngol 2008; 29: 31-6. [CrossRef]

6. Kim JH, Lee EJ, Son EJ. Traumatic Incus Dislocation Into The External Auditory Canal. Otol Neurotol 2013; 34: 28-9. [CrossRef]

7. Delrue S, Verhaert N, Dinther J, Zarowski A, Somers T, Desloovere $C$, et al. Surgical Management And Hearing Outcome Of Traumatic Ossicular Injuries. J Int Adv Otol 2016; 12: 23I-6. [CrossRef] 